\title{
Evaluation of the Latrobe Valley Better Health Injury Prevention Program
}

\author{
L M Day, J Ozanne-Smith, E Cassell, L Li
}

\begin{abstract}
Objective-To evaluate the Latrobe Valley Better Health Injury Prevention Program, a regional community based intervention in south east Victoria, Australia.

Method-The evaluation design was quasiexperimental including preintervention and post-intervention observations in a predominately town dwelling population of approximately 76000 . There was no comparison community. Process measures included key informant interviews. Impact evaluation utilised self reported changes in injury risk and protective factors, gathered by a random household telephone survey. Outcome evaluation was based on five years of

The community based approach to injury prevention has been adopted by Australian programs ${ }^{1}$ seeking to emulate successful Scandinavian programs. ${ }^{2}$ The Latrobe Valley Better Health Injury Prevention Program aimed to utilise this approach to increase public awareness of prevention measures, reduce hazards, and reduce the incidence and severity of injuries in the Latrobe Valley, Victoria. The population (76 000) of this regional area is highly urbanised, with $88 \%$ living in three major towns. ${ }^{3}$

The program targeted home, sports and playground injury prevention, and alcohol misuse among young people. ${ }^{4}{ }^{5}$ We report here the results of program evaluation based on household survey and injury surveillance data for the period May 1992 to June 1996.
\end{abstract} emergency department injury surveillance data for the Latrobe Valley.

Results-The program built strategic partnerships, increasing the emphasis on local safety. Activities were implemented in the targeted areas of home, sport, and playground injuries. Some 47000 educational contacts were made with the community and at least 6000 resource items distributed. There were significant increases in home safety knowledge. Some changes in the areas of playground and sport safety were achieved after partnership development with relevant agencies. Poisson regression models showed significant decreases in the presentation rate for all home injury and for the more severe home injuries.

Conclusion-This study clearly demonstrates the difficulty of conducting robust evaluation in the absence of readily available and reliable data and adequate budgets. The Latrobe Valley Better Health Program activities contributed to structural, environmental, and organisational changes that have the potential to reduce injury. The extent of this contribution beyond that made by the statewide injury prevention strategy is not able to be determined.

(Injury Prevention 2001;7:66-69)

Keywords: safe community; home accidents; athletic injuries; playground accidents

Table 1 Telephone surveys, Latrobe Valley Better Health Project, Victoria

\begin{tabular}{lll}
\hline & Pre-intervention, 1992 & Post-intervention, 1995 \\
\hline Connection rate & $76.8 \%$ & $81 . \%$ \\
Response rate & $76.7 \%$ & $55.5 \%$ \\
Households & 375 & 400 \\
Persons & 1052 & 1182 \\
Proportion of total population & $1.4 \%$ & $1.6 \%$ \\
\hline
\end{tabular}

\section{Methods}

Process evaluation data were obtained from the program officer's diaries, reports and media file, and through semistructured interviews with key individuals.

Pre-intervention and post-intervention observations were conducted through random household telephone surveys in April 1992 and 1995 to gather data for the process (program awareness), impact (knowledge, attitudes, and practices), and outcome (injury in the previous two weeks) evaluation. Survey dimensions and response rates are shown in table 1. Self reported injury rates for the two week period before the surveys were calculated using the total persons surveyed as the denominator. These rates were not age standardised as the ages of injured persons were not recorded.

Emergency department injury data for five years (1991/92 to $1995 / 96)$ were obtained through the Victorian Injury Surveillance System (VISS) at the Latrobe Regional Hospital, the only public hospital within the relatively well defined geographic area of the program. Data collection processes and details of the VISS database have been published. ${ }^{67}$ The surveillance system captured presentations of acute injury on the first attendance. Annual capture rates were $100 \%$ for admissions and not less than $85 \%$ for presentations according to regular audits of the department register. ${ }^{5}$

Targeted injuries were identified by the Injury Surveillance Information System codes for injury in home, sport, and playground locations. ${ }^{8}$ Data on injuries not targeted by the program were extracted as a comparison. Work and road traffic injuries were excluded from all analyses because they were the subject of statewide strategies over the intervention period. Injury incidence data were adjusted for capture rates. 
Table 2 Home safety knowledge and action, Latrobe Valley Better Health Project, Victoria

\begin{tabular}{lll}
\hline Proportion of respondents & 1992 (95\% CI) & 1995 (95\% CI) \\
\hline Able to list safety features of home & $65.9(60.8$ to 70.7$)$ & $79.3(74.9$ to 83.1$)$ \\
Able to list ways their home safety could be improved & $50.7(45.5$ to 55.8$)$ & $47.3(42.3$ to 52.3) \\
Knowing where to purchase safety items & $62.4(57.2$ to 67.3$)$ & $72.0(67.3$ to 76.3$)$ \\
Having purchased safety items in previous 12 months & 42.7 (37.6 to 47.8$)$ & $45.8(40.8$ to 50.8)
\end{tabular}

Rates per 100000 population were calculated using the estimated resident population for the program postcode areas purchased from the Australian Bureau of Statistics. Rates were age standardised to the Victorian population by the direct method. ${ }^{9}$

Linear trends in emergency department presentation rates were estimated using Poisson regression. ${ }^{11}{ }^{11}$ The analyses were conducted separately for all injuries and for more severe injuries (those requiring review, referral, observation, or admission) to examine program impact on injuries of varying severity.

\section{Results}

PROCESS

The key informant interviews revealed that the presence of the program increased the rate of implementation of safety strategies. Links between the injury prevention program and other local organisations became strategic partnerships resulting in increased participation in safety related activities by organisations such as the local municipal council and the police.

There were at least 46000 educational contacts with the community on home injury prevention through a safety display home, a safety display in the hospital emergency department, and a mobile safety product display. In addition, home injury prevention education sessions for professional groups were attended by 170 people. More than 6000 home injury prevention resource items were distributed.

A playground safety education session was undertaken in two consecutive years with the local Primary School Principals' Association (40 members). Playground safety was presented in the local Bachelor of Education (Primary) university course, reaching approximately 60 trainee teachers.

Injury prevention materials were incorporated into the local football coaching courses and sports trainers' programs, reaching approximately 365 coaches and trainers. Sports

Table 3 Emergency department injury presentation frequencies and rates, Latrobe Valley, Victoria, 1991-96

\begin{tabular}{llllll}
\hline & \multicolumn{2}{l}{$\begin{array}{l}\text { Emergency department presentations } \\
\text { (adjusted frequencies) }\end{array}$} & & \multicolumn{2}{l}{$\begin{array}{l}\text { Emergency department presentation } \\
\text { rates/100 000 (age standardised) }\end{array}$} \\
\cline { 2 - 3 } \cline { 5 - 6 } & Targeted injury* & Untargeted injury & & Targeted injury * & Untargeted injury * \\
\hline $1991-92 \dagger$ & 4827 & 1369 & 6121.0 & 1779.2 \\
$1992-93$ & 5178 & 1328 & 6593.7 & 1740.7 \\
$1993-94 \ddagger$ & 4747 & 1180 & & 6076.6 & 1560.1 \\
$1994-95$ & 4554 & 1274 & & 5761.4 & 1670.6 \\
$1995-96$ & 3885 & 1261 & 4821.0 & 1613.0 \\
\hline
\end{tabular}

*Targeted injury=home, sport, and playground injury; untargeted injury=injury not targeted by the program except road and work related injuries which were the subject of statewide campaigns over the intervention period.

†Program commenced May 1992

¥Statewide injury prevention strategy launched September 1994. injury prevention displays reached approximately 880 people. The program used a major sports sponsorship funded by a health foundation to promote player preparation, coach accreditation and codes of conduct for players, supporters, and clubs.

IMPACT

Despite consistent coverage of the program by local media, general awareness of local safety programs increased marginally between the two household surveys $(18.7 \%$ aware of safety programs compared with $20.8 \%, \mathrm{p}=0.42)$. A larger increase in awareness and knowledge was observed for home safety and this appeared to have been translated into action by a small proportion of respondents (table 2). There was a very small increase in the average number of safety features reported per household $(1.9,2.2, \mathrm{p}=0.83)$.

Coinciding with partnership development with local government bodies, nine new community playgrounds were constructed and six pieces of hazardous equipment removed. Tan bark undersurfacing was replaced regularly in municipal playgrounds, and from 1994 a local government maintenance crew conducted monthly playground audits using tick box checklists.

There was no difference in the preintervention and post-intervention surveys in the proportion of respondents able to list ways to prevent sports injury $(72.8 \%, 95 \%$ confidence interval (CI) 68.0 to $77.2 ; 72.5 \%, 95 \%$ CI 67.8 to 76.8 ). Although not directly observed, an increase in the sports safety equipment use, particularly for Australian football, was implied by policy changes and sales data. Partnership development between the program and football clubs coincided with the requirement by four clubs for the under 10 and under 12 year old teams to wear helmets. Low cost mouth guards purchased from the Latrobe Regional Hospital Dental Clinic increased from an average of four to eight per month in the first and second program years respectively.

OUTCOME

There was a non-significant decrease in the rate of self reported injuries recorded in the telephone surveys (62.7/1000 persons, 48.2/ 1000 persons, $\mathrm{p}=0.19)$. The age standardised rate per 100000 persons for emergency department presentations for all targeted unintentional injury fell from 6593.7 in year 1 to

Table 4 Estimated annual trend of emergency department injury presentation rates, Latrobe Valley, Victoria, 1991-96

\begin{tabular}{llllll}
\hline & \multicolumn{2}{l}{ All injuries } & & \multicolumn{2}{l}{ More severe injuries * } \\
\cline { 2 - 3 } \cline { 5 - 5 } Injury type & $\begin{array}{l}\text { Rate } \\
\text { ratio }\end{array}$ & $95 \%$ CI & & $\begin{array}{l}\text { Rate } \\
\text { ratio }\end{array}$ & $95 \%$ CI \\
\hline Home & 0.909 & 0.900 to 0.919 & & 0.923 & 0.910 to 0.936 \\
Playground & 0.999 & 0.966 to 1.034 & & 1.046 & 1.001 to 1.093 \\
Sport & 0.968 & 0.949 to 0.987 & & 0.997 & 0.972 to 1.023 \\
Untargeted & 0.973 & 0.957 to 0.989 & & 1.003 & 0.982 to 1.024 \\
\hline
\end{tabular}

*Those requiring review, referral, observation or admission. tInjury not targeted by the program except road and work related injuries which were the subject of statewide campaigns over the intervention period. 
4821.0 in the final evaluation year (table 3). A decreasing trend in emergency department presentation rates was observed for home, sport, and untargeted injuries (table 4 ). The decrease for home injuries, but not sports injuries, was significantly greater than that for untargeted injuries. The only category in which more severe injuries declined was home injury.

\section{Discussion}

Like other community based program evaluations, ${ }^{101213}$ this evaluation has a number of limitations, and clearly demonstrates the difficulty of conducting robust evaluation when appropriate data are not readily available and inadequate budgets limit evaluation design and activities. Methodological difficulties included poor response rates in the second household survey resulting in demographic differences, and the unknown reliability of self reported safety practices and household features. As is often the case, the community was self selected and measurement of the outcome was at the individual level.

The most significant limitation is the lack of comparison data, constraining conclusions about association of the program with the observed changes in impact and outcome measures. At the time of the study, Latrobe Regional Hospital was the only nonmetropolitan hospital in Australia conducting all age emergency department surveillance. Statewide hospital admissions data that could have provided comparison for more severe injuries were not reliable for this time period due to large fluctuations reflecting changes to health care system funding. ${ }^{7}$ Budgetary constraints precluded the conduct of telephone surveys in a comparison region.

Time series analysis was also not an option since pre-intervention surveillance data were not available due to the close proximity of the start dates for the program and the surveillance system.

Therefore, injury categories not targeted by the program, excluding work and road injury that were targeted by other interventions, were adopted as an internal comparison. Differences between the trends in targeted and untargeted injury were observed for only one targeted injury category: home injury. This was also the area of greatest program activity, as evidenced by the large number of educational contacts and the increased awareness and knowledge demonstrated in the household survey. This compares with the smaller scope of educational activities about playground and sports injury, and no change in knowledge about sports injury reduction.

Changes in patient presentation patterns do not appear to explain the observed injury reductions. Latrobe Regional Hospital remains the only public hospital serving the Latrobe Valley. During the evaluation period, there was only one small ( 45 beds) private hospital serving the region, which had no facilities for outpatient injury management. Anecdotal evidence indicates that there was a decline in the number of general practitioners serving the

\section{Key points}

- The Latrobe Valley Better Health Injury Prevention Program contributed to structural, environmental, and organisational changes with the potential to provide a cumulative benefit in terms of injury reduction.

- A decreasing trend in emergency department presentations for home and sports related injury was observed. The decrease for home injury was significantly greater than the decrease observed in injuries not targeted by the program.

- The extent to which the program contributed to the observed injury reductions beyond the statewide injury prevention strategy could not be determined.

- Future evaluations require reliable data systems and multiple control communities.

area since the late 1980 s, which would tend to increase, rather than decrease, emergency department presentations (Henk Harberts, personal communication).

Statewide injury prevention activities could also explain the differential injury reduction observed in the program. During the last two years of the evaluation period, statewide agencies were implementing the Victorian Injury Prevention Strategy, launched in September 1994. ${ }^{14}$ Home, sport and playground equipment related injury were all included in the state strategy, and the area of greatest activity was home injury prevention. Significant strategies included promotion of safe home design, a major scalds prevention campaign, and subsidised smoke detector installation. Sport and playground safety received less attention. ${ }^{15}$

Notwithstanding the above caveats, the program developed collaborative relationships with local organisations and contributed to structural, environmental, and organisational changes that have the potential to provide a cumulative benefit in terms of injury reduction. The extent of this contribution above that made by the statewide strategy in the latter years of the program is not able to be determined.

Similar evaluations are likely to provide diminishing returns in terms of advancing the understanding of community based programs as an injury prevention strategy. The quasiexperimental design has limitations, even if a comparison community is included. Controlled trials of randomly assigned multiple communities would obviously be more robust. The financial and methodological challenges of such trials are substantial and challenging.

This work was funded by the Victorian Health Promotion Foundation and the National Health and Medical Research Council. The authors are grateful to the program officer, Henk Harberts, and other members of the Latrobe Valley community who participated in the evaluation activities. The Victorian who participated in the evaluation activities. The Victorian
Injury Surveillance System at the Latrobe Regional Hospital Injury Surveillance System at the Latrobe Regional Hospital
provided the high quality injury data. The authors remain provided the high quality injury data. The authors remain
indebted to the project team at MUARC for their respective indebted to the project team at MUARC for their respective
contributions. Professor Peter Vulcan provided enthusiastic 
support throughout the evaluation period and made critical comment on this manuscript.

1 National Safety Council of Australia. Community based injury prevention: a practical guide. South Australia: The injury prevention:

2 Svanstrom L. More Safe Communities programs in Scandanavia have been evaluated: repeating the results Scandanavia have been evaluated: repeating
from Falkoping (letter). Inj Prev 1997;3:230-1.

3 Harvey D, Higgins W. Latrobe Valley Better Health Project: evaluation of nutrition program (1992-1996). Churchill, Australia: Centre for Research-Health Education and Social Sciences, Monash University, 1997.

4 Harberts H. Community cooperation toward a safer future. Moe: Monash University Centre for Rural Health, 1997.

5 Day L, Ozanne-Smith J, Cassell E, et al. Latrobe Valley Better Health Project: evaluation of injury prevention program 19921996. Melbourne: Monash University Accident Research Centre 1997. (Report No 114.)

6 Nolan T, Penny, M. Epidemiology of non-intentional injuries in an Australian urban region: results from injury surveillance. F Paediatr Child Health 1992;28:27-35.

7 Watt GM. Injuries sustained by young people in Victoria, 1986 1992. Melbourne: Monash University Accident Research Centre 1992. (Report No 43.)
8 National Injury Surveillance and Prevention Project coding manual. Adelaide: National Injury Surveillance Unit, 1988. 9 Pollard AH, Yusuf F, Pollard GN. Demographic techniques. Australia: Pergamon Press, 1981.

10 Langley J, Alsop J. Lidkoping Accident Prevention Programme: what was the impact? Inj Prev 1996;2:131-4.

11 Kuhn L, Davidson L, Durkin M. Use of Poisson regression and time series analysis for detecting changes over time in rates of child injury following a prevention program. $A m \mathcal{F}$ Epidemiol 1994;140:943-55.

12 Sanson-Fisher R, Redman S, Hancock L. Developing methodologies for evaluating community-wide health promotion. Health Promotion International 1996;11:227-35.

13 Ozanne-Smith J, Watt G, Day L, et al. Community based injury prevention evaluation: The Safe Living Program (19901996). Melbourne: Monash University Accident Research Centre, 1998. (Report No 131.)

14 Victorian Department of Health and Community Services. Taking injury prevention forward: strategic directions for Victoria. Melbourne: Victorian Department of Health and Community Services, 1994.

15 Victorian Injury Prevention Committee. Taking injury prevention forward: implementation report. Melbourne: Victorian Department of Health and Community Services, rian 1996.

\section{Driver crashes after tortoise bite}

Associated Press reported that a Swiss driver crashed into an oncoming bus after a tortoise bite. The woman was travelling with two tortoises on the passenger seat of her car when one bit her, causing her to swerve across the road and collide with the bus, said police in the northern Swiss state of Solothurn. The only injury was the bite to the woman driver, they said, adding that passengers "of every shape and size" should be properly restrained in vehicles (thanks to CPSlist for this snippet).

\section{Power punch proves fatal}

Ian was a fitness fanatic and self employed electrician living in an English seaside town. He had recently converted one room of his cottage into a new gym. Among the weights and exercise equipment hung a punchbag, suspended from a chain from the ceiling. Little did Ian realize that he had inadvertently managed to combine his hobby with his work. After a Saturday night carousing with his cousin, he came home to show off his new gym. Leading the way, he switched on the lights and casually punched the punchbag. He was knocked to the floor by a bolt of electricity, and died instantly. He had wired the power supply to the punchbag. His best friend said: "He was a brilliant guy. It's crazy that two major parts of his life contributed to his death". You might say he was shockingly fit (Evening Standard (London) and Weston Daily Press, August 1999). 